\title{
Formação, saberes e práticas de ensino dos professores da disciplina de Didática: estado da questão
}

\author{
Training, knowledge and practice of teaching teachers of the \\ Didactic discipline: state of question
}

\author{
Formación, saberes y prácticas de enseñanza de los \\ profesores de la disciplina de Didáctica: estado de la questión
}

Renata Rosa Russo Pinheiro Costa Ribeiro
(iD $h t t p: / / o r c i d . o r g / 0000-0002-1882-808 X$

Rachel Rachelley Matos Monteiro

iD $h t t p: / / o r c i d . o r g / 0000-0001-7704-5299$

Antonio Germano Magalhães Júnior

iD $h t t p: / / o r c i d . o r g / 0000-0002-0988-4207$

\begin{abstract}
Resumo: A temática de investigação versa sobre formação de professores situada como parte central dos debates acerca do desenvolvimento profissional e do trabalho docente. Este artigo teve como objetivo analisar as contribuições das pesquisas sobre formação, saberes e práticas de ensino dos professores da disciplina de Didática nos cursos de licenciatura. Teve como objeto de estudo formação, saberes e práticas de ensino dos professores de Didática na docência universitária. Como metodologia, utilizou-se a pesquisa qualitativa por meio de levantamento bibliográfico, realizado em diferentes instrumentos de busca do tipo Estado da Questão com coleta de dados realizada no Banco de Teses da CAPES, Biblioteca Digital Brasileira de Dissertações e Teses (BDTD), periódicos, anais de eventos científicos e dissertações do Programa de Pós-Graduação em Educação (PPGE) da UECE. O aporte teórico ancorou-se em Gauthier et al (2013), Nóbrega-Therrien e Therrien (2010), Tardif (2010), Sacristán (1999) dentre outros. Conclui-se sobre a necessidade formativa dos professores da disciplina de Didática para o fortalecimento dos saberes pedagógicos tecida no diálogo compartilhado com outros pesquisadores que possibilitarão novas descobertas acerca da formação, dos saberes e da prática dos professores no campo da Didática.
\end{abstract}

Palavras-chave: Formação. Saberes. Práticas de Ensino. Didática.

Abstract: The research theme is about teacher training as the central part of the debates about professional development and teaching work. This article aimed to analyze the contributions of research on training, knowl- 
edge and teaching practices of teachers of the didactics course in undergraduate courses. The object of study was training, knowledge and teaching practices of didactic teachers in university teaching. As a methodology, qualitative research was used by means of a bibliographical survey, carried out in different search tools of the State of the Question type, with data collection carried out at the Bank of Theses of CAPES, Brazilian Digital Library of Dissertations and Theses (BDTD), periodicals , annals of scientific events and dissertations of the Graduate Program in Education (PPGE) of UECE. The theoretical contribution was anchored in Gauthier et al (2013), Nóbrega-Therrien and Therrien (2010), Tardif (2010), Sacristán (1999) among others. We conclude on the formative need of the teachers of the didactic discipline to strengthen the pedagogical knowledge woven in the shared dialogue with other researchers that will make possible new discoveries about the formation, the knowledge and the practice of the teachers in the field of Didactics.

Key-words: Formation. Knowledge. Teaching Practices. Didactics.

Resumen: La temática de investigación versa sobre formación de profesores situada como parte central de los debates acerca del desarrollo profesional y del trabajo docente. Este artículo tuvo como objetivo analizar las contribuciones de las investigaciones sobre formación, saberes y prácticas de enseñanza de los profesores de la disciplina de Didáctica en los cursos de licenciatura. En el caso de los profesores de Didáctica en la docencia universitaria, tuvo como objeto de estudio formación, saberes y prácticas de enseñanza de los profesores de Didáctica. Como metodología, se utilizó la investigación cualitativa por medio de levantamiento bibliográfico, realizado en diferentes instrumentos de búsqueda del tipo Estado de la Cuestión con recolección de datos realizada en el Banco de Tesis de la CAPES, Biblioteca Digital Brasileña de Disertaciones y Tesis (BDTD), periódicas , anales de eventos científicos y disertaciones del Programa de Postgrado en Educación (PPGE) de la UECE. El aporte teórico se ancló en Gauthier et al (2013), Nóbrega-Therrien y Therrien (2010), Tardif (2010), Sacristán (1999) entre otros. Se concluye sobre la necesidad formativa de los profesores de la disciplina de Didáctica para el fortalecimiento de los saberes pedagógicos tejida en el diálogo compartido con otros investigadores que posibilitará nuevos descubrimientos acerca de la formación, de los saberes y de la práctica de los profesores en el campo de la Didáctica.

Palabras clave: Formación. Conocimiento. Prácticas de Enseñanza. Didáctica.

\section{Introdução}

A temática de investigação versa sobre formação de professores situada como parte central dos debates acerca do desenvolvimento profissional e do trabalho docente. Nesse sentido, optamos por desenvolver o estudo na área partindo da premissa de que a formação docente ancora-se nas dimensões pessoal, profissional e institucional que ganha um significado mais amplo quando aponta análises que possuem como força motriz as reflexões sobre o percurso formativo como ponto de partida para a apropriação dos conhecimentos sistematizados e específicos no ensino superior. Em relação a investigação sobre a docência universitária, Barros e Dias (2016, p. 44), afirmam sobre a "[...] necessidade de estudos críticos sobre essa temática, visando obter subsídios que contribuam para a busca de caminhos formativos para a docência, adequada à realidade contemporânea da educação superior". A docência universitária é entendida como campo de atuação no ensino superior que necessita de um repertório de conhecimentos considerando na sua trajetória 
de desenvolvimento profissional primando pela consolidação dos saberes docentes e das práticas educativas. Tardif (2000, p. 15) percebe que:

[...] a prática profissional dos professores é heterogênea ou heterônoma no tocante aos objetivos internos da ação e aos saberes mobilizados. Por exemplo, quando observamos professores trabalhando em sala de aula, na presença dos alunos, percebemos que eles procuram atingir, muitas vezes de forma simultânea, diferentes tipos de objetivos: procura controlar o grupo motivá-lo, levá-lo a se concentrar em uma tarefa, ao mesmo tempo em que dão uma atenção particular a certos alunos da turma, procuram organizar atividades de aprendizagem, acompanhar a evolução da atividade, dar explicações, fazer com que os alunos compreendam e aprendam etc.

Entendemos que o trabalho docente articulado aos saberes, a formação e as práticas de ensino dos professores constituem elementos essenciais para uma ação reflexiva que atende as necessidades de sua formação inicial nos cursos de licenciaturas. Nesse sentido, a dimensão pedagógica e o trabalho docente são indicadores para uma formação sustentada nas condições objetivas e subjetivas da profissionalização docente que realiza e que se concretiza como princípio norteador de uma práxis educativa. Segundo Tardif (2010) saberes, práticas de ensino e formação são mobilizados na prática cotidiana, no exercício de sua autoridade em sala de aula e nas relações estabelecidas entre os diferentes sujeitos durante o processo de ensino e aprendizagem.

Com base nessas reflexões, surgiu o interesse de conhecer as produções científicas que abordassem a temática formação de professores com a finalidade de obter elementos teórico-metodológicos que contribuam para a busca de caminhos formativos, para a apropriação dos saberes dos professores e das práticas de ensino do profissional docente. Nessa perspectiva, partimos de uma questão central: como é constituída a formação, os saberes e as práticas de ensino dos professores da disciplina de Didática nos Cursos de Licenciatura? Responder a esse questionamento pode nos ajudar a compreender sobre a realidade atual da formação docente tendo como fundamento epistemológico a formação dos professores da disciplina de Didática no ensino superior e provocar reflexões acerca de novos corpus de conhecimentos pedagógicos relacionados à prática docente. Essas discussões fortalecem o debate sobre os saberes docentes capazes de mobilizar os conhecimentos durante sua prática docente relacionando-os com as situações pedagógicas no contexto do trabalho profissional. (TARDIF, 2010).

O objeto de estudo versa sobre formação, saberes e práticas de ensino dos professores de Didática na docência universitária. Desse modo, para evidenciar as contribuições teóricas para o campo do conhecimento sobre formação de professores, se faz necessária essa investigação denominada Estado da Questão (EQ), sobre o objeto de estudo por meio de um inventário da produção científica que teve por objetivo analisar as contribuições das pesquisas brasileiras sobre formação, saberes e práticas de ensino dos professores da disciplina de Didática nos cursos de licenciatura. O EQ possibilita ao pesquisador conhecer o 
panorama de estudos e pesquisas na área de interesse, que acontece mediante criterioso levantamento bibliográfico realizado em diferentes instrumentos de busca que subsidia o processo de investigação no campo teórico-metodológico.

Para atender ao objetivo, a metodologia adotada foi a pesquisa qualitativa por meio do levantamento bibliográfico denominado o Estado da Questão (EQ). Para coleta de dados, utilizamos o Portal de Periódicos da Coordenação de Aperfeiçoamento de Pessoal de Nível Superior (CAPES) e a Biblioteca Digital Brasileira de Teses e Dissertações (BDTD), mantida pelo Instituto Brasileiro de Informação em Ciência e Tecnologia (IBICT), que reúne, em um só portal, as teses e as dissertações defendidas em todo o País e por brasileiros no exterior. Optamos pela realização do Estado da Questão (EQ) tendo como marco temporal o período de 2010 a 2015, com a intenção de contribuir com a composição de novos estudos no cenário acadêmico. Para Nóbrega-Therrien e Therrien (2010, p. 34): "a finalidade do EQ é a de levar o pesquisador a registrar, com suporte em um rigoroso levantamento bibliográfico, como se encontra o tema ou o objeto de sua investigação no atual estado da ciência ao seu alcance". Pensando na elaboração do EQ, elegemos alguns questionamentos: O que as produções científicas sinalizam sobre a formação de professores? Qual foco não foi priorizado nos estudos inventariados? Dessa forma, consideramos as pesquisas que analisassem, no âmbito da docência universitária, a formação, os saberes e as práticas dos professores da disciplina de Didática nos cursos de licenciatura.

Na seção a seguir, detalhamos a metodologia da investigação apontando o caminho percorrido para o mapeamento do $E Q$, destacando as pesquisas que se aproximam do objeto de investigação. Em seguida, apresentamos as produções e as temáticas de acordo com a busca realizada nos artigos publicados em periódicos da CAPES; nos anais de eventos científicos e, nas dissertações do Curso de Mestrado do Programa de Pós-Graduação em Educação (PPGE) do Centro de Educação (CED) da Universidade Estadual do Ceará (UECE). Ao final, as considerações com destaque para as constatações a partir do EQ e as referências realizado nesse estudo.

\section{Metodologia da investigação e o caminho percorrido para o mapeamento do Estado da Questão (EQ)}

A formação é entendida como um processo inerente de qualquer profissão, em especial a formação de professores constitui como uma etapa e um processo contínuo de saberes e práticas. Quando destacamos sobre a formação nos cursos de licenciatura, percebemos diferentes caminhos na dimensão individual e coletiva durante a trajetória profissional para a constituição desse ser professor. Desta feita, o interesse pela temática surgiu da necessidade de discutir sobre a formação, os saberes e as prática de ensino dos professores universitários, no âmbito do ensino superior. Nesse sentido, para pesquisar sobre o percurso formativo no contexto brasileiro e em destaque no cenário cearense, consideramos que o Estado da Questão (EQ) permite ao pesquisador delimitar, caracterizar as concepções sobre a temática em estudo e sobre o objeto de investigação na intenção de apresentar as 
aproximações dos estudos com as abordagens inéditas da temática central da pesquisa. Essa aproximação adveio de uma pesquisa realizada no grupo de pesquisa do PPGE/CED/ UECE com o apoio de uma universidade universidade pública estadual, que teve como objetivo cartografar o percurso formativo dos professores dos cursos de licenciatura tendo como objeto de estudo a constitição dos saberes docentes durante sua trajetória profisisonal e a mobilização de suas práticas de ensino que desenvolvem na docência universitária.

Assim, para compreendermos o percurso formativos dos professores nos porpomos a investigar se fez necessário evidenciar o EQ partindo da premissa que uma temática investigativa compreende um mapeamento detalhado de produções dos pesquisadores sobre este objeto, é um exercício que o pesquisador vai também tomando conhecimento do que existe publicado e se posicionando diante das produções em análise. Segundo Nóbrega-Therrien e Therrien (2010, p.35), a realização do Estado da Questão " [...] requer uma compreensão ampla da problemática em foco fundada nos registros dos achados científicos e nas suas bases teórico-metodológicas acerca da temática". Nesse estudo, direcionamos nosso olhar para os professores das disciplinas de Didática em decorrência da revelância do seu objeto de estudo que se refere ao processo de ensino e de aprendizagem que se materializa nos fundamentos; nas condições de ensino; nos conhecimentos adquiridos sobre o como, para quem, o que e por que ensinar, elementos constituintes do percurso formativo necessários à ação docente.

Desse modo, para descrever detalhadamente os caminhos trilhados para o mapeamento do Estado da Questão, a metodologia utilizada foi a pesquisa qualitativa, por meio do levantamento bibliográfico realizado em diferentes instrumentos de busca para a coleta e análises dos dados, tendo com fundamentos teóricos os estudos de Barros e Dias (2016); Gauthier el al (2013); Nóbrega-Therrien e Therrien (2010) e Tardif (2010).

Para dar início ao EQ realizamos o mapeamento das publicações dos artigos publicados em periódicos nacionais, nas teses e dissertações utilizando como base o banco de dados da Biblioteca Digital Brasileira de Dissertações e Teses (BDTD), disponível no site http:// bdtd.ibict.br/vufind/; dos periódicos da Coordenação de Aperfeiçoamento de Pessoal de Nível Superior (CAPES); compreendendo os anos de 2010 a 2015; nos anais do Encontro Nacional de Didática e Prática de Ensino (ENDIPE), todos no eixo temático: Didática e Práticas de Ensino; no banco de dados das dissertações do Mestrado Acadêmico em Educação do Programa de Pós-Graduação (PPGE/CED/UECE), disponível em http://www.uece.br/ppge/.

No itinerário de buscas das teses e dissertações fizemos primeiramente a leitura dos títulos e resumos dos trabalhos inventariados. Após esse momento, realizamos a busca no objeto de estudo, analisando os objetivos, os procedimentos metodológicos, o referencial teórico e as conclusões. Posteriormente, a esse mapeamento, selecionamos os trabalhos que revelaram analogias com o nosso objeto de investigação e realizamos a leitura de alguns trabalhos mais aproximados da temática, utilizando como filtro o recorte temporal de 2010 a 2015. O critério de seleção da demarcação temporal correspondeu a promulgação das Diretrizes Curriculares Nacionais (DCN) para a Formação de Professores para a Educação Básica, em nível superior, curso de licenciatura, de graduação plena (BRASIL, 2002). Esse documento orienta os cursos para 
mudanças na estrutura, na organização curricular e no funcionamento para todos os cursos de licenciatura no âmbito brasileiro. Desse modo, o recorte temporal abrangeu as pesquisas mais recentes e que podem contribuir com sugestões e propositivas conceituais para a formação de professores tendo como suporte a política pública docente visando uma reorganização e adaptação da formação de professores, com base nos modelos formativos nos cursos de licenciaturas no ensino superior, na medida em que corroboramos com a ideia de Tardif (2010), quando afirma que a formação docente é um tema que vem sendo discutido nos últimos anos como foco central as bases teórico-práticas que fundamentam o trabalho e os saberes docentes.

Os critérios para a inclusão dos trabalhos pesquisados foram os estudos relacionados á área de Educação utilizando os descritores relacionados à nossa temática de investigação pautada no aporte teórico da pesquisa: formação, saberes e práticas. Em segunda, idenficamos a necessidade de incluir outros filtros devido a quantidade revelante dos achados; assim, selecionamos docência universitária, práticas pedagógicas, prática no ensino superior; saberes docentes; Didática; Didática nos cursos de licenciatura, porque estavam relacionados diretamente ao nosso objeto, em relação às opções fornecidas pela base de dados. Os critérios para a exclusão foram as pesquisas que não abordavam o filtro sobre o assunto Formação de Professores. Todos os dados foram registrdos no diário de bordo que poderá ser utilizado por outros pesquisadores interesssados nas temáticas em apreço.

No Quadro 1, apresentamos os trabalhos de teses e dissertações considerando os descritores: quantidade de trabalho, tipo (D: dissertação; T: tese;), quantidade de trabalho relacionado com o tema, trabalho selecionado e ano.

Quadro 1 - Teses e Dissertações considerando descritor, quantidade de trabalho, quantidade de trabalho relacionado com o tema, trabalho selecionado.

\begin{tabular}{|c|c|c|c|}
\hline \multirow{2}{*}{ Descritor } & $\begin{array}{c}\text { Quantidade } \\
\text { de Trabalho (D/T) }\end{array}$ & $\begin{array}{c}\text { Quantidade de trabalho } \\
\text { relacionado com o tema }\end{array}$ & Trabalho selecionado \\
\hline \multirow{2}{*}{ Docência universitária } & \multirow{2}{*}{$32 / 13$} & 05 & 02 \\
\cline { 3 - 4 } & \multirow{2}{*}{$144 / 45$} & 07 & 02 \\
\hline \multirow{2}{*}{ Práticas Pedagógicas } & \multirow{2}{*}{$39 / 15$} & 03 & 01 \\
\hline \multirow{2}{*}{$\begin{array}{c}\text { Prática no } \\
\text { ensino superior }\end{array}$} & \multirow{2}{*}{$131 / 28$} & 03 & 03 \\
\hline \multirow{2}{*}{ Saberes docentes } & \multirow{2}{*}{$350 / 32$} & 09 & 03 \\
\cline { 3 - 4 } & & 08 & 04 \\
\hline \multirow{2}{*}{ Didática } & $748 / 164$ & 13 & 03 \\
\hline & & 03 & 02 \\
\hline \multirow{2}{*}{$\begin{array}{c}\text { Didática nos Cursos de licencia- } \\
\text { tura }\end{array}$} & 1741 & 01 & 02 \\
\hline TOTAL & & 01 & 01 \\
\hline
\end{tabular}

Fonte: Elaborado pelos autores. 
Interpretando o Quadro 1, elegemos os achados e fizemos uma leitura inicial dos títulos a fim de selecionar os quais têm aproximação com nosso objeto de estudo e identificamos hum mil e setecentos e quarenta e hum (1741) trabalhos compreendendo dissertações e teses. Dentre estes, temos hum mil quatrocentos e quarenta e quatro (1444) dissertações e, duzentos e noventa e sete (297) teses.

Após o refinamento dos títulos e das palavras-chave, selecionamos os trabalhos na busca sobre a problematização; os aportes teóricos; os objetivos; a metodologia e os resultados. Com base nesses elementos, selecionamos um total de 61 trabalhos para a leitura dos resumos relacionados diretamente com a nossa temática. Dentre estes, selecionamos 26 para uma leitura mais detalhada a fim de identificar elementos semelhantes com nosso objeto e com o objetivo geral do nosso estudo. Verificamos que embora a busca tenha apresentado uma grande quantidade de trabalhos relacionados aos descritores elencados nesse estudo, percebemos que a maioria das temáticas abordavam aspectos epistemológicos diretamente ao trabalho docente, sem tecer consideração diretivas sobre a constituição da formação, dos saberes docentes e das práticas de ensino dos professores de Didática no ensino superior.

Diante desses dados, consideramos que a categoria formação de professores tem maior destaque nas pesquisas científicas que trazem como centro das discussões a necessidade de pensar sobre o percurso formativo na perspectiva do desenvolvimento profissional e do exercício no magistério no cenário da docência universitária. Na concepção de Imbernón (2011) a formação de professores é um processo que se sustenta ao longo da vida escolar e acadêmica que envolve as condições de trabalho participação e decisões da profissão docente.

O Quadro 2 a seguir, apresenta as informações das teses e dissertações utilizando ainda os mesmos descritores: docência universitária, práticas pedagógicas, prática no ensino superior, didática, saberes docentes, didática nos cursos de licenciatura, destacando título, autor(a), instituição e ano de publicação.

Quadro 2 - Teses e Dissertações considerando descritor, tipo (T/D), título, autor (a), instituição/ano de publicação.

\begin{tabular}{|c|c|c|c|c|}
\hline Descritor & $\begin{array}{c}\text { Tipo } \\
\text { (T/D) }\end{array}$ & Título & Autor (a) & $\begin{array}{c}\text { Instituição } \\
\text { Ano de } \\
\text { Publicação }\end{array}$ \\
\hline \multirow{5}{*}{$\begin{array}{c}\text { Docência univer- } \\
\text { sitária }\end{array}$} & $\mathrm{T}$ & $\begin{array}{c}\text { Docência universitária: represen- } \\
\text { tações sociais das constituições } \\
\text { subjetivas }\end{array}$ & $\begin{array}{c}\text { Tatiana Machiavelli Carmo } \\
\text { Souza }\end{array}$ & $\begin{array}{c}\text { UNESP } \\
2012\end{array}$ \\
\cline { 2 - 5 } & $\mathrm{T}$ & $\begin{array}{c}\text { Movimentos da profissionalidade: a } \\
\text { tessitura da docência universitária }\end{array}$ & $\begin{array}{c}\text { Ana Carla Hollweg } \\
\text { Powaczuk }\end{array}$ & $\begin{array}{c}\text { UFSM } \\
2012\end{array}$ \\
\cline { 2 - 5 } & $\mathrm{D}$ & $\begin{array}{c}\text { Docência universitária e formação } \\
\text { pedagógica: um olhar para a Univer- } \\
\text { sidade Estadual de Londrina }\end{array}$ & $\begin{array}{c}\text { Marcela Pedroso de Ca- } \\
\text { margo }\end{array}$ & $\begin{array}{c}\text { UEL } \\
2012\end{array}$ \\
\hline
\end{tabular}




\begin{tabular}{|c|c|c|c|c|}
\hline \multirow{3}{*}{$\begin{array}{l}\text { Prática Pedagó- } \\
\text { gica }\end{array}$} & $\mathrm{D}$ & $\begin{array}{l}\text { Formação docente: reverberações } \\
\text { possíveis na prática pedagógica }\end{array}$ & Maribel Susane Selli & $\begin{array}{l}\text { UFRS } \\
2011 \\
\end{array}$ \\
\hline & $\mathrm{D}$ & $\begin{array}{l}\text { Docência no ensino superior: refle- } \\
\text { xões sobre práticas pedagógicas e } \\
\text { competências }\end{array}$ & Nilton Luiz Souto & $\begin{array}{l}\mathrm{PUC} / \mathrm{SP} \\
2011\end{array}$ \\
\hline & $\mathrm{D}$ & \begin{tabular}{|l|} 
Ressignificando o saber docente pelo \\
olhar da prática pedagógica: um estu- \\
do de professores mestres pela UEPB
\end{tabular} & Débora Cristina Santos & $\begin{array}{l}\text { UEPb } \\
2013\end{array}$ \\
\hline \multirow{5}{*}{$\begin{array}{l}\text { Prática no ensi- } \\
\text { no superior }\end{array}$} & $\mathrm{T}$ & $\begin{array}{c}\text { Os saberes pedagógicos dos profes- } \\
\text { sores do ensino superior: o cotidiano } \\
\text { de suas práticas }\end{array}$ & Mara Leite Simões & $\begin{array}{l}\text { UFPb } \\
2010\end{array}$ \\
\hline & $\mathrm{T}$ & \begin{tabular}{|c|} 
Percursos de profissionalização do- \\
cente no ensino superior: trajetória e \\
renovação na prática pedagógica \\
\end{tabular} & Liandra Pereira & $\begin{array}{l}\text { Uni Católica do } \\
\text { Paraná } \\
2010\end{array}$ \\
\hline & $\mathrm{D}$ & $\begin{array}{c}\text { Representações sociais: rupturas e } \\
\text { protagonismos nas práticas docentes } \\
\text { no ensino superior }\end{array}$ & Eliana Curvelo Rodrigues & $\begin{array}{l}\text { UNESP } \\
2011\end{array}$ \\
\hline & $\mathrm{D}$ & $\begin{array}{c}\text { Discursos sobre a prática: o pro- } \\
\text { cesso de formação do professor } \\
\text { do ensino superior sem a formação } \\
\text { pedagógica }\end{array}$ & $\begin{array}{c}\text { Marcia de Oliveira Torres } \\
\text { Vanderlei }\end{array}$ & $\begin{array}{l}\text { Universidade } \\
\text { Metodista São } \\
\text { Paulo } \\
2012\end{array}$ \\
\hline & $\mathrm{D}$ & $\begin{array}{c}\text { A prática educativa no ensino supe- } \\
\text { rior da UFMA: concepções teóricas e } \\
\text { implicações metodológicas no Curso } \\
\text { de Licenciatura em Pedagogia }\end{array}$ & Bergson Pereira Utta & $\begin{array}{c}\text { UFMA } \\
2011\end{array}$ \\
\hline \multirow[b]{2}{*}{ Didática } & $\mathrm{T}$ & $\begin{array}{l}\text { Percursos da Didática da história } \\
\text { para os anos iniciais no Brasil }\end{array}$ & Tiago Costa Sanches & 2015 \\
\hline & $\mathrm{D}$ & $\begin{array}{l}\text { Desafios da didática nas licencia- } \\
\text { turas: um estudo com professores } \\
\text { formados entre cinco e dez anos }\end{array}$ & $\begin{array}{l}\text { Elaine Emiliano de Mo- } \\
\text { raes }\end{array}$ & $\begin{array}{l}\text { USP } \\
2012\end{array}$ \\
\hline \multirow{4}{*}{$\begin{array}{l}\text { Saberes docen- } \\
\text { tes }\end{array}$} & $\mathrm{T}$ & $\begin{array}{l}\text { A díade saberes e práticas docentes: } \\
\text { um estudo de suas inter-relações }\end{array}$ & Ana Teresa Silva Sousa & $\begin{array}{l}\text { UFRN } \\
2011\end{array}$ \\
\hline & $\mathrm{D}$ & $\begin{array}{c}\text { Formação, produção de saberes e } \\
\text { da identidade docente: desafios e } \\
\text { possibilidades de redimensionamen- } \\
\text { to das práticas pedagógicas }\end{array}$ & $\begin{array}{l}\text { José Amarildo Alves da } \\
\text { Silva }\end{array}$ & $\begin{array}{l}\text { UFPb } \\
2013\end{array}$ \\
\hline & $\mathrm{D}$ & $\begin{array}{l}\text { A constituição da identidade profis- } \\
\text { sional docente: formação e saberes }\end{array}$ & $\begin{array}{l}\text { Miriam Raquel Nilson } \\
\text { Backes Spengler }\end{array}$ & $\begin{array}{l}\text { UNISINOS } \\
2010\end{array}$ \\
\hline & $\mathrm{D}$ & $\begin{array}{c}\text { Trajetórias de formação e a constru- } \\
\text { ção dos saberes docentes: investi- } \\
\text { gando tempos e espaços formadores } \\
\text { a partir da experiência de formação } \\
\text { inicial }\end{array}$ & Nelda Alonso dos Santos & $\begin{array}{l}\text { Universidade } \\
\text { Federal de Pe- } \\
\text { lotas } \\
2010\end{array}$ \\
\hline \multirow{2}{*}{$\begin{array}{l}\text { Didática nos } \\
\text { Cursos de licen- } \\
\text { ciatura }\end{array}$} & $\mathrm{T}$ & \begin{tabular}{|c|} 
Coerência e contradição: o conteúdo \\
e a forma no exercício da docência de \\
didática nos cursos de licenciatura
\end{tabular} & $\begin{array}{l}\text { Maria Janine Dalpiaz } \\
\quad \text { Reschke }\end{array}$ & $\begin{array}{l}\text { UNISINOS } \\
2014\end{array}$ \\
\hline & $\mathrm{D}$ & \begin{tabular}{|c|} 
A Didática nos Cursos de Licenciatu- \\
ra em Pedagogia nas Universidades \\
Públicas do Ceará: concepções e \\
possibilidades
\end{tabular} & $\begin{array}{l}\text { Charmânia Freitas de } \\
\text { Sátiro }\end{array}$ & $\begin{array}{l}\text { UFC } \\
2013\end{array}$ \\
\hline
\end{tabular}

Fonte: Elaborado pelos autores. 
Interpretando os dados do Quadro 2, das 19 produções investigadas considerando as categorias e descritores, identificamos as produções que tem relação direta com formação, saberes e práticas, contando com (07) Teses e doze (12) Dissertações. Como resultados dessa busca, temos a descrição dos descritores: Docência universitária, com 2 Teses e 1 Dissertação; Prática pedagógica, com 3 Dissertações; Prática no ensino superior, com 1 Tese e 3 Dissertações; Didática com 1 Tese e 1 Dissertação; Saberes docentes, com 1 Tese, 3 Dissertações; Didática nos cursos de licenciatura com 1 Tese e 1 Dissertação. Diante desses dados quantitativos, concluímos que na nossa busca, existem mais trabaIhos de dissertações de mestrado do que teses de doutorado que pontuam as categorias anteriormente descritas.

Analisando a dissertação de Camargo (2012): "Docência universitária e formação pedagógica: um olhar para a Universidade Estadual de Londrina”, a autora teve como objetivo geral refletir sobre a docência no âmbito da universidade e a formação pedagógica dos professores nessa instituição de ensino. Os dados da sua pesquisa apontaram que a instituição tem uma preocupação com qualidade da formação pedagógica dos professores. No entanto, afirmou que existem algumas ações isoladas para a melhoria da formação docente, mas que de fato não se consolidam como ações efetivas visando à valorização dos profissionais.

O estudo de Spengler (2010): "A constituição profissional docente: formação e saberes" teve como objetivo identificar como o sujeito professor se constitui como docente. Utilizou os aportes teóricos em Tardif (2007), Cunha (2006), Gauthier (1998), Pimenta (2002) e Garcia (1999). A autora concluiu sua pesquisa apontando sobre e relevância dos saberes experienciais para a constituição docente.

Os estudos de Vanderlei (2012) revelaram que o processo de formação dos professores do ensino superior, ocorre, em grande medida, a partir de seu passado escolar e da sua convivência profissional. Como lembra Therrien (2012, p. 109) "[...] discursar sobre saberes, tempo de educação e trabalho docente entre os profissionais de ensino requer uma postura de reflexão colaborativa sobre o que somos, como trabalhamos e para que atuamos".

Em relação ao nosso objeto de estudo (formação, saberes e práticas de ensino dos professores de Didática na docência universitária), identificamos a pesquisa de Reschke (2014): "Coerência e contradição: o conteúdo e a forma no exercício da docência de didática nos cursos de licenciatura" teve como objetivo compreender como os docentes das disciplinas de Didática Geral e Específica em cursos de licenciatura constituíram suas trajetórias e como estas ecoam na sua prática pedagógica com seus alunos na formação inicial. A autora concluiu que a docência universitária é feita de contradições profissionais e desafios do trabalho docente e, que os professores percebem que suas ações são complexas porque fazem parte de contextos sociais que os ajudam a legitimar sua prática pedagógica.

Desse modo, inferimos que os dados das pesquisas até aqui apresentadas revelaram que os conhecimentos, as experiências e os saberes advindos do exercício da profissão 
são relevantes para a docência e para a constituição do ser professor, quando mobilizados e articulados aos saberes da docência no Ensino Superior, valorizando os saberes elaborados na prática da profissão de cada área específica tecidas nos saberes experienciais do trabalho docente estabelecidas as relações subjetivas durante seu percurso formativo, sua trajetória de vida pessoal e profissional. Essas análises vão ao encontro da pesquisa realizada por Maciel, Magalhães Júnior e Bezerra (2018), intitulada "Formação, saberes e práticas avaliativas: um estado da questão", que evidenciou que para conhecer a constituição dos saberes docentes torna-se necessária uma reflexão sobre o percurso formativo e suas práticas pedagógicas no âmbito das instituições de ensino superior. Esse pressuposto se fundamenta na ideia de Gauthier et al (2013), ao considerar que os docentes possuem um repertório de conhecimentos materializados nos saberes profissionais mobilizados na prática de ensino.

\section{O que revelam os artigos publicados em Periódicos da CAPES}

A inquietação científica em encontrar outras pesquisas relacionadas à temática formação de professores evidenciou na busca de trabalhos utilizando outro banco de dados de igual relevância nacional.

O mapeamento dos artigos em periódicos nacionais ocorreu junto ao Portal da CAPES, através da base de dados SciELO, utilizando as palavras-chave por nos possibilitar o acesso a periódicos reconhecidos pela credibilidade científica de suas publicações no contexto nacional na área da Educação e Formação de Professores, utilizado os periódicos indexados com Qualis A1, B1 e B2 validados por pares que privilegiam as temáticas de formação, saberes e práticas dos professores nas instituições de ensino superior. Essa busca seguiu os critérios semelhantes da pesquisa em apreço, considerando as categorias, os descritores e o período temporal. A busca nesses periódicos qualificados pela CAPES se justifica porque estes estratos são considerados como bem avaliados nos cenários internacionais e nacionais e pelos pares dos Programas de Pós-Graduação em Educação no contexto brasileiro.

A seguir, alocamos no Quadro 3, os artigos localizados no Portal dos periódicos da CAPES apresentando as produções, destacando autor (a), título do artigo, periódico e ano de publicação, considerando o marco temporal de 2010 a 2015.

Quadro 3 - Periódicos da CAPES, considerando autor (a), título do artigo, periódico, ano de publicação.

\begin{tabular}{|c|c|c|c|}
\hline Autor $(\mathrm{a})$ & Título do artigo & Periódico & $\begin{array}{c}\text { Ano de } \\
\text { Publicação }\end{array}$ \\
\hline $\begin{array}{c}\text { CARVALHO, Adriano Vieira } \\
\text { de }\end{array}$ & $\begin{array}{c}\text { Os saberes docentes nas visões de } \\
\text { Paulo Freire e Maurice Tardif: uma } \\
\text { contribuição. }\end{array}$ & $\begin{array}{c}\text { Ensenanza Aprendizaje } \\
\text { de las Ciencias }\end{array}$ & 2014 \\
\hline $\begin{array}{c}\text { PINTO, Maria das Graças } \\
\text { Gonçalves }\end{array}$ & $\begin{array}{c}\text { O lugar da prática pedagógica e dos } \\
\text { saberes docentes na formação de } \\
\text { professores }\end{array}$ & Education & 2010 \\
\hline
\end{tabular}




\begin{tabular}{|c|c|c|c|}
\hline $\begin{array}{c}\text { TAKAHASHI, Bruno; BAS- } \\
\text { TOS, Fernando. }\end{array}$ & $\begin{array}{c}\text { Quais saberes são mobilizados para } \\
\text { suprir as lacunas na formação inicial } \\
\text { referentes à História da Ciência? }\end{array}$ & $\begin{array}{c}\text { Enseñanza y Aprendiza- } \\
\text { je de las Ciencias }\end{array}$ & 2011 \\
\hline $\begin{array}{c}\text { DE PAULA Marques, Fer- } \\
\text { nanda; RODRIGUES Maria } \\
\text { Inês Ribas }\end{array}$ & $\begin{array}{c}\text { O desenvolvimento de saberes pro- } \\
\text { fissionais: a formação com as disci- } \\
\text { plinas pedagógicas de licenciandos } \\
\text { brasileiros }\end{array}$ & $\begin{array}{c}\text { Revista electrónica de } \\
\text { enseñanza de las ciên- } \\
\text { cias }\end{array}$ & 2015 \\
\hline $\begin{array}{c}\text { MARTIN, Pura Lúcia Oliver; } \\
\text { ROMOMANOWSKI, Joana } \\
\text { Paulin }\end{array}$ & $\begin{array}{c}\text { A didática na formação pedagógica } \\
\text { de professores }\end{array}$ & 2010 \\
\hline $\begin{array}{c}\text { LA GARZA, Susana Cuevas } \\
\text { de }\end{array}$ & $\begin{array}{c}\text { La docencia universitaria a través del } \\
\text { conocimiento profesional práctico: } \\
\text { pistas para la formación }\end{array}$ & $\begin{array}{c}\text { Revista Electrónica } \\
\text { Sinéctica }\end{array}$ & 2013 \\
\hline
\end{tabular}

Fonte: Elaborado pelos autores.

De acordo com o Quadro 3, temos os seguintes trabalhos que se aproximam de nosso estudo. A pesquisa de Pinto (2010): "O lugar da prática pedagógica e dos saberes docentes na formação de professores" teve como objetivo refletir sobre a formação de professores analisando os saberes constituídos durante a pedagógica dos docentes. Utilizou como fundamentos Cunha (2002), Tardif (2001, 2002), Pimenta (2000), Pimenta e Anastasiou (2002). Apontou em suas conclusões que o movimento da reflexão da prática dos professores constitui como destaque importante no processo formativo que tem em seu elemento fundante a forma de pensar e agir sobre a docência.

O texto "La docencia universitaria a través del conocimiento profesional práctico: pistas para la formación" da autora La Garza (2013), destaca algumas concepções sobre docência, prática e desenvolvimento profissional. Sua pesquisa teve como sujeitos sete professores que refletiram sobre os saberes e a variedade de suas práticas que existem no contexto universitário. A autora concluiu que quando os professores possuem uma formação pedagógica desenvolvem um hábito de refletir sobre sua própria prática permitindo identificar e solucionar melhor os problemas de ensino e de aprendizagem. Para ajudar a interpretar os posicionamentos da autora, trazemos Sacristán (1999, p. 47) ao afirmar que as ações dos sujeitos resultam da compreensão do sentido e significado em decorrência de sua racionalidade, "o que fazemos tem relação com aquilo que pensamos e vice-versa".

O texto "A didática na formação pedagógica de professores" de Martin e Romanowski (2010) destacou como objetivo discutir a didática, as prioridades, a tendência e o papel da didática na formação dos professores nos cursos de licenciatura. A pesquisa teve como sujeitos professores e coordenadores dos cursos de licenciatura de cinco universidades públicas e particulares do Paraná analisando os Projetos Pedagógicos dos Cursos.

Diante das leituras e das análises dos trabalhos pesquisados, os artigos em periódicos da CAPES, as teses e as dissertações evidenciaram que os Cursos de licenciaturas tendem a oferecer mais disciplinas específicas voltadas para as metodologias das áreas de conhecimento e que os professores de didática têm uma inclinação a priorizar os elementos pedagógicos no processo da aprendizagem, como centro do estudo o aluno como 
indivíduo ativo capaz de dominar os processos de aprender. Desse modo, corroborando com as pesquisas descritas, os estudos de Ribeiro, Monteiro e Magalhães Júnior (2017), revelam que a formação docente nos cursos de licenciatura possibilita os conhecimentos necessários à constituição dos saberes pedagógicos imprescindíveis à prática de ensino. Percebendo que

Os saberes utilizados no exercício da docência e a necessidade de superação do distanciamento da teoria e da prática reforça a valorização de saberes específicos e dos saberes da experiência, da formação inicial e continuada durante o percurso formativos dos professores. (RIBEIRO; MAGALHÃES JUNIOR, 2017, p. 34).

Nessa perspectiva, defendemos que a formação de professores nos cursos de licenciatura revela o reconhecimento da especificidade dos saberes para o exercício do magistério, relacionado aos conhecimentos pedagógicos com as dimensões teóricas e práticas materializadas nas experiências cotidianas de trabalho docente situado e contextualizado. Nessa esteia de considerações apontadas pelos pesquisadores, reafirmamos que os trabalhos apresentam alguns elementos similares com o objeto de estudo porque traz para o centro das discussões as categorias centrais do nosso estudo que envolve a formação, os saberes docentes, as práticas de ensino e, como estes se constituem professores na docência universitária.

\section{Mapeando as produções do Encontro Nacional de Didática e Prática de Ensino (EN- DIPE) no período de 2010 a 2014}

Em relação aos eventos científicos de reconhecimento internacional e nacional para os pesquisadores e profissionais na área da educação, temos os encontros da Associação Nacional de Pesquisa e Pós-Graduação em Educação (ANPED) e o Encontro Nacional de Didática e Prática de Ensino (ENDIPE). No entanto, nossa atenção para a busca dos trabaIhos foi voltada para os encontros do ENDIPE. O critério de escolha pela busca desse evento científico se justificou pela tradição cientifica no cenário nacional e internacional onde estão presentes as pesquisas relevantes e reconhecidas pelos pares no campo da Didática.

Nesse sentido, apresentamos o resultado da busca nos anais dos trabalhos do Encontro Nacional de Didática e Prática de Ensino (ENDIPE), no período de 2010 a 2014. Vale a pena ressaltar que o ENDIPE desde o final da década de 1980, ocorre de dois em dois anos em diferentes estados do Brasil, portanto os trabalhos aqui apresentados e comentados fazem parte dos encontros que corresponderam especificamente ao período de 2010 a 2014 . Temos como pressuposto que nos eventos científicos as pesquisas desenvolvidas no campo da Didática tendem a apresentar uma contextualização social, histórica e política sobre o percurso formativo dos professores que lecionam a disciplina de Didática nos cursos de licenciatura no cenário universitário e coloca em discussão sobre o lugar e o papel da Didática na formação inicial e continuada de professores. Como base nessa premissa, ressaltamos que 
o campo da Didática é considerado por pesquisadores como uma área de maior relevância para quem se interessa pela formação dos professores das disciplinas pedagógicas, que tem como essência a natureza do processo de ensino e de aprendizagem. Partindo dessa discussão, surgiu o nosso interessem em pesquisar mais diretamente os trabalhos para o campo da Didática, que na análise de Marin e Pimenta (2018, p. 9), os ENDIPES:

realizados nos últimos 38 anos a cada dois anos constituem fóruns específicos de estudos e pesquisas que apontam para as reconfigurações constantes sobre a especificidade da didática frente a esses desafios, assim como têm ampliado o diálogo com as demais áreas que estudam o ensino, apesar desse movimento também mostrar certa dispersão temática, epistemológica, disciplinar e de foco da Didática.

Numa contextualização histórica, O ENDIPE surgiu em 1983 como resultado de um Seminário titulado “A Didática em Questão", com profissionais da educação debatendo sobre o ensino e a Didática, na perspectiva epistemológica e política, que teve como objetivo "[...] problematizar e discutir a Didática, sua orientação epistemológica e política bem como a natureza de suas propostas para o campo do ensino" (DALBEN, LEAL, SANTOS, 2010, p. 5). Considerando o surgimento do ENDIPE e destacando sua relevância para o campo da educação, Pimenta e Lima (2010, p. 71), ressaltam como:

um verdadeiro espaço de formação contínua para formadores pelo exercício de reflexão coletiva que propicia pelo aprender com o grupo busca de alternativas pedagógicas e pela discussão das políticas educacionais e seus determinantes e dos caminhos da educação

Nos apropriando do surgimento do ENDIPE, situamos que nas décadas de 80 e 90 o cenário educacional presenciava nos movimentos dos profissionais da educação discursos sobre a constituição e legitimidade da Didática como área de conhecimento retratados nas pesquisas e estudos teórico-metodológicos pautados nas reflexões sobre a dimensões política, técnica e humana; sobre o papel da escola; dos métodos, das técnicas e das práticas do processo de ensino e de aprendizagem. Naquele período, as discussões contribuíram para fortalecimento de uma Didática crítica e transformadora com relevância aos elementos epistemológicos traduzidos na relação teoria e prática e do exercício docente. Assim, com a intenção de nos aproximarmos das pesquisas realizadas em um evento científico, realizamos a busca nos anais e nos e-books do ENDIPE no período de 2010 a 2014 e identificamos diferentes organizações dos trabalhos apresentados, caracterizados em comunicação oral, paines, posters, mesas redondas e simpósios. A seguir, vamos apresentar a estrutura de cada evento relacionando e comentando os trabalhos que tiveram aproximações com nosso objeto de investigação.

O XV ENDIPE, realizado no período de 20 a 23 de abril de 2010, teve como tema central: "Convergências e tensões no campo da formação e do trabalho docente: Políticas e práticas educacionais". Todos os trabalhos citados no quadro 4 encontram-se nos-books, distribuidos em 6 livros. No livro 1, com as temáticas: alfabetização e letramento; arte-educação; educação 
infantil; ensino da língua portuguesa e ensino de línguas estrangeiras. No livro 2, com as temáticas: educação de jovens e adultos; educação de pessoas com deficiências: altas habilidades e condutas típicas; educação do campo; educação, gênero e sexualidade; educação indígena; relações raciais e educação. No livro 3, as temáticas são avaliação educacional; educação a distância e tecnologia da comunicação e informação; educação profissional e tecnológica; ensino superior; políticas educacionais. No livro 4, didática, formação de professores, trabalho docente. As temáticas educação ambiental; educação em ciências; educação em espaços-não escolares; educação matemática fazem parte do livro 5. As temáticas do livro 6, são currículo; ensino de educação física; ensino de história; ensino de geografia.

O XVI ENDIPE, realizado no período de 23 a 26 de julho de 2012, teve como tema central "Didática e Práticas de ensino: compromisso com a escola pública, laica, gratuita e de qualidade". Os trabalhos estão contemplados em três livros. No livro 1, com o título: políticas educacionais e impactos na escola e na sala de aula. No livro 2, o título versa sobre políticas de formação inicial e continuada de professores. Temos o livro 3, com o título: didática e práticas de ensino na realidade escolar contemporânea: constatações, análises e proposições.

O XVII ENDIPE, realizado no período de 11 a 14 de novembro de 2014 teve como tema central "A didática e prática de ensino nas relações entre a escola, a formação e a sociedade". Todos os 1700 artigos estão organizados em quatro livros. No 1, com a temática: Didática e Prática de Ensino na relação com a Escola. No livro 2: Didática e Prática de Ensino na relação com a Formação de Professores. No livro 3: Didática e Prática de Ensino na relação com a Sociedade. No livro 4: Didática e Prática de Ensino: diálogos sobre a Escola, a Formação de Professores e a Sociedade.

Diante da leitura dos títulos de todos os trabalhos nos XV, XVI e XVII ENDIPES, apresentamos no quadro 4 os trabalhos que posssuem aproximações com nosso objeto de estudo.

Quadro 4 - Trabalhos apresentados no Encontro Nacional de Didática e Prática de Ensino (ENDIPE), considerando tema, ano, autor, trabalho, instituição/local, considerando o marco temporal de 2010 a 2014.

\begin{tabular}{|c|c|c|c|c|}
\hline Ano & Tema & Autor & Trabalho & Instituição/ Local \\
\hline \multirow{4}{*}{2010} & \multirow{4}{*}{$\begin{array}{l}\text { Convergências e ten- } \\
\text { sões no campo da } \\
\text { formação e do traba- } \\
\text { lho docente: } \\
\text { políticas e práticas } \\
\text { educacionais. }\end{array}$} & $\begin{array}{l}\text { VEIGA, Ilma Passos Alen- } \\
\text { castro. }\end{array}$ & $\begin{array}{l}\text { Por dentro da Didática: um } \\
\text { retrato de três pesquisas. }\end{array}$ & \multirow{4}{*}{\begin{tabular}{|c|} 
Universidade \\
Federal de Minas \\
Gerais (Belo \\
Horizonte (MG)
\end{tabular}} \\
\hline & & $\begin{array}{l}\text { MARTINS, Pura Lúcia } \\
\text { Oliver; ROMANOWSKI } \\
\text { Joana Paulin. }\end{array}$ & \begin{tabular}{|c|} 
A Didática na formação pe- \\
dagógica de professores nas \\
novas propostas para os cursos \\
de licenciatura.
\end{tabular} & \\
\hline & & MARCONDES, Maria Inês & $\begin{array}{c}\text { Pesquisa sobre o saber prático } \\
\text { dos professores: perspectivas e } \\
\text { limites dos auto-estudos. }\end{array}$ & \\
\hline & & $\begin{array}{c}\text { NUNES, Célia Maria Fer- } \\
\text { nandes }\end{array}$ & $\begin{array}{c}\text { O professor e os saberes do- } \\
\text { centes: algumas possibilidades } \\
\text { de análise das pesquisas. }\end{array}$ & \\
\hline
\end{tabular}




\begin{tabular}{|c|c|c|c|c|}
\hline \multirow{3}{*}{2012} & \multirow{3}{*}{$\begin{array}{c}\text { Didática e Práticas de } \\
\text { Ensino: compromisso } \\
\text { com a escola pública, } \\
\text { laica, gratuita e de } \\
\text { qualidade }\end{array}$} & CANDAU, Vera Maria & $\begin{array}{c}\text { Didática: entre saberes, sujeitos } \\
\text { e práticas. }\end{array}$ & \multirow{3}{*}{$\begin{array}{l}\text { Universidade Es- } \\
\text { tadual de Campi- } \\
\text { nas (UNICAMP). } \\
\text { Campinas - SP }\end{array}$} \\
\hline & & $\begin{array}{c}\text { CARVALHO, Anna Maria } \\
\text { Pessoa de. }\end{array}$ & \begin{tabular}{|c|}
$\begin{array}{l}\text { Prática de ensino: seu estatuto } \\
\text { epistemológico, disciplinar e de } \\
\text { prática. }\end{array}$ \\
\end{tabular} & \\
\hline & & MARIN, Alda Junqueira & $\begin{array}{l}\text { A Didática, as práticas de en- } \\
\text { sino e alguns princípios para a } \\
\text { pesquisa e à docência. }\end{array}$ & \\
\hline \multirow{8}{*}{2014} & \multirow{8}{*}{\begin{tabular}{|} 
A Didática e a Prá- \\
tica de Ensino nas \\
relações entre escola, \\
formação de profes- \\
sores e sociedade
\end{tabular}} & $\begin{array}{l}\text { CALAZANS, Andrea An- } \\
\text { drea; VERÍSSIMO, } \\
\text { Mariana. }\end{array}$ & $\begin{array}{c}\text { A Didática e a complexidade do } \\
\text { trabalho docente: da relação } \\
\text { com o saber à noção de ativida- } \\
\text { de. }\end{array}$ & \multirow{8}{*}{$\begin{array}{c}\text { Universidade Es- } \\
\text { tadual do Ceará } \\
\text { (UECE) } \\
\text { Fortaleza- Ceará } \\
\end{array}$} \\
\hline & & $\begin{array}{l}\text { SOUZA, Ruth Catarina C. } \\
\text { Ribeiro de; } \\
\text { MAGALHÃES. Solange } \\
\text { Martins Oliveira. }\end{array}$ & \begin{tabular}{|c|} 
A Didática e as escolhas epis- \\
temológicas na formação de \\
professores e sua prática.
\end{tabular} & \\
\hline & & $\begin{array}{l}\text { CONCEIÇÃO, Juliana } \\
\text { Santos da; NUNES, Célia } \\
\text { Maria Fernandes. }\end{array}$ & $\begin{array}{l}\text { A docência universitária e os } \\
\text { saberes do professor iniciante. }\end{array}$ & \\
\hline & & ARAUJO, Lucélia Costa. & \begin{tabular}{|c|}
$\begin{array}{c}\text { A formação docente mediando } \\
\text { os significados e os sentidos } \\
\text { sobre o ser professor. }\end{array}$ \\
\end{tabular} & \\
\hline & & $\begin{array}{c}\text { RODRIGUES, Cicera Si- } \\
\text { neide Dantas; THERRIEN, } \\
\text { Jacques. }\end{array}$ & $\begin{array}{c}\text { Experiências formativas de pro- } \\
\text { fessores universitários: disposi- } \\
\text { ções norteadoras de } \\
\text { concepções e práticas pedagó- } \\
\text { gico-científicas. }\end{array}$ & \\
\hline & & $\begin{array}{l}\text { SOARES, Luciana de } \\
\text { Sousa Lima. }\end{array}$ & \begin{tabular}{|c|}
$\begin{array}{c}\text { Histórias de vidas vividas: uma } \\
\text { análise do processo de consti- } \\
\text { tuição docente. }\end{array}$ \\
\end{tabular} & \\
\hline & & $\begin{array}{l}\text { RODRIGUES, Marcelle } \\
\text { Pereira. }\end{array}$ & $\begin{array}{c}\text { O (des)lugar da Didática nos } \\
\text { processos de (auto)formação } \\
\text { docente: o que revelam os } \\
\text { saberes da experiência? } \\
\end{array}$ & \\
\hline & & $\begin{array}{c}\text { FARIA, Tereza Cristina } \\
\text { Leandro de. }\end{array}$ & $\begin{array}{c}\text { Os saberes de professores } \\
\text { sobre Didática: reflexões sobre } \\
\text { o ensinar. }\end{array}$ & \\
\hline
\end{tabular}

Fonte: Elaborado pelos autores.

Diante dos achados no quadro 4, citamos a pesquisa de Veiga et al. (2010) com o título "Por dentro da Didática: um retrato de três pesquisas", teve como objetivo analisar as práticas pedagógicas dos professores de Didática em suas aulas em um curso de formação em três universidades públicas e privadas. Teve como sujeitos cinco professores dessas instituições de ensino. Como resultados da pesquisa, as autoras apontaram a fragilidade na formação inicial dos alunos; a necessidade de superar a racionalidade técnica durante as aulas observadas e o distanciamento da disciplina de Didática com o exercício da docência e no processo de formação.

O estudo de Martins e Romanowski (2010) intitulado "A Didática na formação pedagógica de professores nas novas propostas para os cursos de licenciatura"; objetivou refletir sobre o lugar da Didática nos cursos de formação de licenciatura nas universidades 
públicas e privadas do estado do Paraná. Como sujeitos fizeram parte dessa pesquisa professores das referidas instituições. Teve como pesquisa documental a análise das Diretrizes Curriculares Nacionais (2002). As autoras concluíram que a Didática tem destaque no contexto das novas diretrizes curriculares e nas propostas para os cursos de licenciaturas. No entanto, afirmaram que a Didática perdeu espaço na dimensão ampla e uma valorização das disciplinas específicas nos cursos de formação.

A investigação desenvolvida por Conceição e Nunes (2014) teve como título "A docência universitária e os saberes do professor iniciante". O objetivo do estudo foi investigar o perfil, os saberes e a ação dos professores de uma instituição pública do Estado de Minas Gerais. De acordo com os dados coletados, as autoras identificaram quatro saberes que mobilizam a ação docente: disciplinar ou do conteúdo; das relações entre professor e aluno; da experiência docente e da prática profissional e o saber adquirido nas relações constituídas na instituição. Com esse estudo, concluíram que os saberes constituídos pelos professores nas diversas tarefas realizadas na instituição de ensino são materializados nas soluções para a compreensão sobre o fazer-se docente. Ao encontro dessa ideia da pesquisa das autoras, Almeida (2012) considera que pensar no processo formativo dos professores no ensino superior precisa levar em consideração o ambiente de sua atuação.

O estudo de Soares (2014), com o título "Histórias de vidas vividas: uma análise do processo de constituição docente", objetivou investigar como os professores se constituíram e permanecem professores. Segundo as narrativas dos sujeitos, os dados revelaram que a constituição docente é legitimada a partir das transformações e condições sociais em constantes ressignificados.

O trabalho de Rodrigues (2014), "O (des)lugar da didática nos processos de (auto) formação docente: o que revelam os saberes da experiência?" teve como objetivo analisar como os discurso sobre os saberes das experiências dos professores considerando os elementos didáticos. O estudo teve aporte teórico em Tardif (2000, 2012), Gauthier (2006), Libâneo (2013), Marin (2005). Com base nos discursos de professores da rede pública de ensino, a autora concluiu que os saberes da experiência são validados para a ação docente e que é preciso superar o lugar da didática nas falas dos professores.

Como resultado das leituras dos trabalhos do ENDIPEs evidenciamos que as pesquisadoras são unânimes ao afirmarem sobre a necessidade de formação sólida na área do campo da Didática considerando que a aprendizagem docente acontece durante o exercício da docência que aponta para a consolidação de um repertório de conhecimentos e saberes necessários próprios do ensino que se referem as habilidades e as atitudes na ação pedagógica constituídos na profissionalização docente.

\section{Dissertações do Curso de Mestrado (PPGE/UECE)}

Continuando com o mapeamento das publicações científicas relacionado ao nosso objeto de estudo nesse EQ apresentamos a busca realizada nas dissertações do Curso de 
Mestrado do Programa de Pós-Graduação em Educação (PPGE) do Centro de Educação (CED) da Universidade Estadual do Ceará (UECE). O criterio de escolha nesse locus investigativo refere-se ao interesse de socializar as pesquisas realizadas pelos pares como reconhecimento dos estudos no cenário insittucional de nossa atuação profissional.

Esclarecemos que, até o presente momento dessa produção, as dissertações do Curso de Mestrado do PPGE/UECE ainda não se encontram na base de dados da BDTD. Por esse motivo, nossa busca foi realizada no acervo digital disponível no seguinte endereço http://www.uece.br/ppge/index.php/teses-e-dissertacoes/dissertacoes. Para a seleção dos trabalhos do Mestrado, seguimos os mesmos critérios desses estudo e seguimos os mesmos passo para a realização do mapeamento dos artigos dos periídos da CAPES. Primeiramente realizamos a leitura dos títulos e que objetivou identificar as pesqusas que contribuíssem com as discussões sobre o nosso objeto de investigação. Nessa busca, para a exclusão das dissertações usamos como critérios os trabalhos das linhas de pesquisa que versavam sobre Ensino e suas Tecnologias; Arte, Memória e Formação; Desenvolvimento Docente, Currículo e Inovação; Formação, Profissão e Práticas Educativas em Saúde; Aprendizagem e Subjetividade no Percurso de Formação e Prática Docente; Política e Gestão Educacional; Tecnologias Digitais em Educação; Marxismo como Ontologia do Ser Social; Formação do Professor no Contexto do Capitalismo Contemporâneo, segundo as informações contidas no site do PPGE/CED/UECE.

Desse modo, com base no mapeamento das dissertações, elaboramos o quadro 5 que apresenta a quantidade dos trabalhos, considerando a turma, total de trabalho defendido, trabalho selecionado, trabalho selecionado com a temática no período de 2010 a 2015.

Quadro 5 - Quantidade das Dissertações do Curso de Mestrado em Educação (PPGE/CED/UECE), considerando turma, total de trabalho defendido, trabalho selecionado, trabalho selecionadas com a temática.

\begin{tabular}{|c|c|c|c|}
\hline Turma & $\begin{array}{c}\text { Total de } \\
\text { trabalho defendido }\end{array}$ & Trabalho selecionado & $\begin{array}{c}\text { Trabalho selecionado } \\
\text { com a temática }\end{array}$ \\
\hline 2010 & 17 & 00 & 00 \\
\hline 2011 & 24 & 03 & 01 \\
\hline 2012 & 26 & 03 & 01 \\
\hline 2013 & 27 & 01 & 00 \\
\hline 2014 & 28 & 02 & 02 \\
\hline 2015 & 18 & 02 & 01 \\
\hline TOTAL & 140 & 11 & 05 \\
\hline
\end{tabular}

Fonte: Elaborado pelos autores.

Interpretando o quadro 5, identificamos um total de 140 dissertações no período investigado e os 05 trabalhos que foram selecionados que tinmham uma aproximação com nosso objeto de estudo. Ainda de acordo com os dados do qaudro 5, observamos que apesar de um número significativo de estudos referentes à formação de professores e do- 
cência universitária percebemos pouca expressividade nas pesquisas referentes ao percurso formativo dos professores nos cursos de licenciatura e para o campo da Didática. Essa análise nos conduz a afirmar que "[...] é preciso ressaltar que há poucos estudos e obras consagradas aos saberes dos professores. Trata-se de um campo de pesquisa novo por isso, relativamente inexplorado, inclusive pelas próprias ciências da educação" (TARDIF, 2010, p. 32). Corroborando ainda o posicionamento do autor, compreendemos que o saber docente se constitui "[...] um constructo social produzido pela racionalidade concreta dos atores por suas deliberações, racionalizações e motivações que constituem a fonte se seus julgamentos, escolhas e decisões". (TARDIF, 2010, p. 223).

O estudo inventariado em relação a quantidade das dissertações possibilitou eleger os trabalhos que utilizaram as categorias percurso formativo; saberes docentes e práticas dos prfoessores nos cursos de licenciaturas. De acordo com os dados descritos no quadro 5, destacamos a seguir as dissertações com ênfase nas categorias formação, saberes e práticas dos professores nos cursos de licenciatura.

Quadro 6 - Dissertações do Curso Mestrado em Educação (PPGE/UECE) considerando as categorias percurso formativo; saberes docentes e práticas dos prfoessores nos cursos de licenciaturas.

\begin{tabular}{|c|c|c|}
\hline Ano & Título & Autor (a) \\
\hline 2010 & ----------- & ------ \\
\hline 2011 & $\begin{array}{c}\text { Processos formativos e a constituição da } \\
\text { docência online: o universo paralelo de } \\
\text { Alice }\end{array}$ & Sinara Socorro Duarte Rocha \\
\hline 2012 & $\begin{array}{c}\text { A formação docente e a constituição dos } \\
\text { saberes dos professores de história de Icó } \\
- \text { CE. }\end{array}$ & Maria Nahir Batista Ferreira \\
\hline 2014 & $\begin{array}{c}\text { Formação, saberes e práticas dos pro- } \\
\text { fessores da área de ensino de história no } \\
\text { curso de história da UECE em Fortaleza. }\end{array}$ & Augusto Ridson de Araújo Miranda \\
\hline 2015 & $\begin{array}{c}\text { Saberes, práticas e formão: uma cartogra- } \\
\text { fia dos professores da área de "história e } \\
\text { ensino" da FECLESC/UECE }\end{array}$ & $\begin{array}{c}\text { Maria Terla Silva Carneiro dos } \\
\text { Santos }\end{array}$ \\
\hline
\end{tabular}

Fonte: Elaborado pelos autores.

Diante do quadro 6, escolhemos as pesquisas que de fato se aproximavam de nossa temática investigativa e identificamos 4 trabalhos. Os estudos de Rocha (2011), Ferreira (2012), Miranda (2014) e Santos (2015) revelaram argumentos semelhantes sobre a diversidade de repertórios de conhecimentos consolidados durante todo o percurso formativo dos professores e que os saberes docentes são mobilizados na prática pedagógica. Apesar dessa evidência, os autores também apontaram que nem todos os professores privilegia- 
vam seus saberes pedagógicos o que indica consequências limitadoras em suas práticas junto às disciplinas pedagógicas.

As pesquisas de Miranda (2014) e Santos (2015) tiveram como objetivos analisar como foram constituídos os percursos de formação e como os saberes docentes foram mobilizados nas práticas pedagógicas dos professores dos cursos de História e Matemática, respectivamente. Os autores concluíram que os percursos formativos legitimaram os saberes docentes, no entanto em alguns momentos da docência universitária sentem fragilidade teóricas na sua prática pedagógica nos cursos de licenciaturas.

O que podemos constatar diante dos resultados das pesquisas do PPGE que os trabalhos possuem aproximações teórico-práticos quando se referem aos percursos formativos; consideram que os elementos constitutivos da docência que se reportam para além da trajetória de vida, permenando os caminhos de suas experiências acadêmicas e profissionais, com sentidos e significados para a epistemologia da prática docente. Reafirmamos que esses achados nas pesquisas das dissertações do PPGE/UECE fortalecem a nossa intenção em pesquisar sobre a docência universitária, tendo como foco central a constituição do percurso formativo dos professores que implica descrever os processos, as escolhas, as decisões, as trajetórias pessoais e profissionais que levaram os sujeitos a se constituírem professores estabelecendo assim as conexões sociais tecidas em seus diferentes contextos profissionais e educacionais.

\section{Conclusão}

Ao retomamos as questões iniciais desse texto: $O$ que as produções científicas sinalizam sobre a formação de professores? Qual o foco não foi privilegiado? Como é constituída a formação, os saberes e as práticas de ensino dos professores da disciplina de Didática nos Cursos de Licenciatura?, Percebemos que as produções elencadas nesse EQ apontaram para o distanciamento das discussões sobre o percurso formativo dos professores da disciplina de Didática.

Os estudos revelaram que a constituição docente é desenvolvida nos diversos contextos e momentos históricos de sua trajetória ao longo de toda a vida pessoal e profissional. Assim, identificamos que os trabalhos corroboram para nosso objeto de estudo porque o percurso formativo é tecido em contexto escolares e universitários com significados para o trabalho docente e revelaram a necessidade de uma sólida formação no âmbito das instituições de ensino superior com o locus privilegiado e apropriado para uma preparação profissional docente. A análise dos resultados também destacou que durante a docência universitária os professores da disciplina de Didática utilizam principalmente os saberes da experiência e os saberes específicos da sua área inicial de formação, mas que não são suficientes para sua prática nos cursos de licenciatura produzidos na articulação de outros saberes docentes. 
Diante do exposto, constatamos que os achados do mapeamento sobre a temática formação de professores possibilitou momentos de reflexividade sobre formação, saberes e práticas dos professores da disciplina de Didática nos cursos de licenciatura que corroboram sobre a importância do lugar que ocupa como área de conhecimento e como uma disciplina pedagógica que tem como elementos contituintes o processo de ensino e aprendizagem. O diálogo compartilhado com outros pesquisadores possibilita novas descobertas e reflexões críticas acerca da formação, dos saberes e da prática dos professores no campo da Didática, principalmente se levamos em consideração seu percurso formativo para a docência universitária.

Concluímos que a elaboração do Estado da Questão revelou a necessidade de uma discussão mais profunda do nosso objeto de estudo, visando a melhoria na delimitação, nas categorias teóricas e da abordagem teórico-metodológica. Portanto, diante desse desafio, afirmamos a importância da continuidade dos estudos que dizem respeito ao percurso formativo dos professores para a docência universitária que pode contribuir com o desenvolvimento profissional docente. 


\section{Referências}

ALMEIDA, Maria Izabel. Formação do professor no ensino superior: desafios e políticas educacionais. São Paulo: Editora Cortez, 2012.

ARAUJO, Lucélia Costa. A formação docente mediando os significados e os sentidos sobre o ser professor. In: ENCONTRO NACIONAL DE DIDÁTICA E PRÁTICA DE ENSINO-ENDIPE, 7., 2014, Fortaleza. Anais do XVII Encontro nacional de didática e prática de ensino-ENDIPE. Fortaleza: EdUECE, 2014.

BARROS, Conceição de Maria Pinheiro; DIAS, Ana Maria lório. A formação pedagógica de bacharéis na educação superior: construindo o Estado da Questão. Revista Educação em Questão, Natal, RN, v. 54, n. 40, jan/abr, 2016.

BRASIL. RESOLUÇÃO CNE/CP No 1, de 18 de Fevereiro de 2002. Institui Diretrizes Curriculares Nacionais para a Formação de Professores da Educação Básica, em nível superior, curso de licenciatura, de graduação plena.

CALAZANS, Andrea; VERÍSSIMO, Mariana. A Didática e a complexidade do trabalho docente: da relação com o saber à noção de atividade. In: ENCONTRO NACIONAL DE DIDÁTICA E PRÁTICA DE ENSINO-ENDIPE, 7., 2014, Fortaleza. Anais do XVII Encontro nacional de didática e prática de ensino-ENDIPE. Fortaleza: EdUECE, 2014.

CAMARGO, Marcela Pedroso de. Docência universitária e formação pedagógica: um olhar para a Universidade Estadual de Londrina. 2012. 125 f. Dissertação (Mestrado em Educação) - Programa de Pós-Graduação em Educação, Universidade Estadual de Londrina. Centro de Educação, Comunicação e Artes. Londrina, Paraná, 2012.

CANDAU, Vera Maria. Didática: entre saberes, sujeitos e práticas. In: ENCONTRO NACIONAL DE DIDÁTICA E PRÁTICA DE ENSINO-ENDIPE, 6., 2012, Campinas. Anais do XVI Encontro nacional de didática e prática de ensino-ENDIPE. Campinas: UNICAMP, 2012.

CARVALHO, Anna Maria Pessoa de. Prática de ensino: seu estatuto epistemológico, disciplinar e de prática. In: ENCONTRO NACIONAL DE DIDÁTICA E PRÁTICA DE ENSINO-ENDIPE, 6., 2012, Campinas. Anais do XVI Encontro nacional de didática e prática de ensino-ENDIPE. Campinas: UNICAMP, 2012

DALBEN, Julio Emilio Diniz Pereira; LEAL, Leiva de Figueiredo Viana; SANTOS, Lucíola Licínio de Castro Paixão. Convergências e tensões no campo da formação e do trabalho

docente: políticas e práticas educacionais. In: ENCONTRO NACIONAL DE DIDÁTICA E PRÁTICA DE ENSINO, 5., 2010, Belo Horizonte. Anais do XV Encontro Nacional de Didática e Prática de Ensino-ENDIPE: Belo Horizonte: UFMG, 2010.

GAUTHIER, Clermont; MARTINEAU, Sthéfane; DESBIENS, Jean-François; MALO, Annie; SIMARD, Denis. Por uma teoria da pedagogia: pesquisas contemporâneas sobre o saber docente. 3. ed. ljuí: Unijui, 2013.

IMBERNÓN, Francisco. Formação docente e profissional: formar-se para a mudança e a incerteza. 9. ed. São Paulo: Cortez, 2011. 
LA GARZA, Susana Cuevas de. La docencia universitaria a través del conocimiento profesional práctico: pistas para la formación. Revista Electrónica Sinéctica, Tlaquepaque, n. 41, jun. 2013.

LIBÂNEO, José Carlos. Formação de professores e didática para o desenvolvimento humano. Educação \& Realidade. Porto Alegre, RS, v. 40, n. 2, p. 629-650, abr/jun, 2015.

MACIEL, Alessandra de Oliveira; MAGALHÃES JÚNIOR, Antonio Germano; BEZERRA, Sarah. Formação, saberes e práticas avaliativas: um estado da questão. Revista Série-Estudo. Campo Grande, MS, v. 23, n. 48, p. 91-109, mai/ago. 2018.

MARCONDES, Maria Inês. Pesquisa sobre o saber prático dos professores: perspectivas e limites dos auto-estudos. In: ENCONTRO NACIONAL DE DIDÁTICA E PRÁTICA DE ENSINO, 5., 2010, Belo Horizonte. Anais do XV Encontro Nacional de Didática e Prática de Ensino-ENDIPE: Belo Horizonte: UFMG, 2010.

MARIN, Alda Junqueira. A Didática, as práticas de ensino e alguns princípios para a pesquisa e à docência. In: ENCONTRO NACIONAL DE DIDÁTICA E PRÁTICA DE ENSINO-ENDIPE, 6., 2012, Campinas. Anais do XVI Encontro nacional de didática e prática de ensino-ENDIPE. Campinas: UNICAMP, 2012.

MARIN, Alda Junqueira; PIMENTA, Selma Garrido. Didática: teoria e pesquisa. 2. ed. Araraquara: Junqueira \& Marin, 2018; Fortaleza: UECE, 2018.

MARTINS, Pura Lúcia Oliver; ROMOMANOWSKI, Joana Paulin. A didática na formação pedagógica de professores. Revista Educação, Porto Alegre, RS, v. 33, n. 3, p. 205-212, 2010.

MARTINS, Pura Lúcia Oliver; ROMANOWSKI, Joana Paulin. A Didática na formação pedagógica de professores nas novas propostas para os cursos de licenciatura. In: ENCONTRO NACIONAL DE DIDÁTICA E PRÁTICA DE ENSINO, 5., 2010, Belo Horizonte. Anais do XV Encontro Nacional de Didática e Prática de Ensino-ENDIPE: Belo Horizonte: UFMG, 2010.

MUSSI, Amali de Angelis. Profissionalidade docente no ensino superior: construção de saberes no contexto das práticas. In: ENCONTRO NACIONAL DE DIDÁTICA E PRÁTICA DE ENSINO-ENDIPE, 7., 2014, Fortaleza. Anais do XVII Encontro Nacional de Didática e Prática de Ensino-ENDIPE: Fortaleza: EdUECE, 2014

NÓBREGA-THERRIEN, Silvia Maria; THERRIEN, Jacques. O estado da questão: aportes teórico-metodológicos e relatos de sua produção em trabalhos científicos. In: FARIAS, Isabel Maria Sabino de; NUNES, Joao Batista Carvalho; NÓBREGA-THERRIEN, Silvia Maria. Pesquisa científica para iniciantes: caminhando no labirinto. Fortaleza: EdUECE, 2010.

NUNES, Célia Maria Fernandes. O professor e os saberes docentes: algumas possibilidades de análise das pesquisas. In: ENCONTRO NACIONAL DE DIDÁTICA E PRÁTICA DE ENSINO, 5., 2010, Belo Horizonte. Anais do XV Encontro Nacional de Didática e Prática de Ensino-ENDIPE: Belo Horizonte: UFMG, 2010.

PIMENTA, Selma Garrido; LIMA, Maria Socorro Lucena. Estágio e Docência. 5. ed. São Paulo: Cortez, 2010. 
PINTO, Maria das Graças Gonçalves. O lugar da prática pedagógica e dos saberes docentes na formação de professores. Revista Acta Scientiarum. Education. Maringá, PR, v. 32, n. 1, p. 111$117,2010$.

RESCHKE, Maria Janine Dalpiaz. Coerência e contradição: o conteúdo e a forma no exercício da docência de didática nos cursos de Licenciatura. 2014. 127 f. Tese (Doutorado em Educação) - Universidade do Vale do Rio dos Sinos, São Leopoldo, 2014.

RIBEIRO, Renata Rosa Russo Pinheiro Costa; MONTEIRO, Rachel Rachelley Matos; MAGALHÃES JÚNIOR, Antonio Germano. Docência universitária no curso de licenciatura em Letras: relação entre saberes, formação e disciplinas pedagógicas. Revista Expressão Católica, Quixadá, CE, v. 6, n. 2, jul/dez, 2017.

RODRIGUES, Marcelle Pereira. O (des)lugar da didática nos processos de (auto)formação docente: o que revelam os saberes da experiência? In: ENCONTRO NACIONAL DE DIDÁTICA E PRÁTICA DE ENSINO-ENDIPE, 7., 2014, Fortaleza. Anais do XVII Encontro Nacional de Didática e Prática de Ensino-ENDIPE: Fortaleza: EdUECE, 2014.

SACRISTÁN, José Gimeno. Poderes instáveis da educação. Porto Alegre: Artes Médicas Sul, 1999.

SOARES, Luciana de Sousa Lima. Histórias de vidas vividas: uma análise do processo de constituição docente. In: ENCONTRO NACIONAL DE DIDÁTICA E PRÁTICA DE ENSINO-ENDIPE, 7., 2014, Fortaleza. Anais do XVII Encontro Nacional de Didática e Prática de Ensino-ENDIPE: Fortaleza: EdUECE, 2014.

SPENGLER, Míriam Raquel Nilson Backes. A constituição da identidade profissional docente: formação e saberes. 2010. 101 f. Dissertação (Mestrado em Educação) - Programa de Pós-Graduação em Educação, Universidade do Vale do Rio dos Sinos, São Leopoldo, 2010.

TAKAHASHI, Bruno; BASTOS, Fernando. Quais saberes são mobilizados para suprir as lacunas na formação inicial referentes à história da Ciência? Revista Ensenanza Aprendizaje de las Ciencias, Bogotá, v. 6, n. 2, p. 63-70, 2011.

TARDIF, Maurice. Saberes docentes e formação profissional. Petrópolis: Vozes, 2010.

TARDIF, Maurice. Saberes profissionais dos professores e conhecimentos universitários. Revista Brasileira de Educação. Jan/Fev/Mar/Abr, 2000, № 13.

THERRIEN, Jacques. Docência profissional: a prática de uma racionalidade pedagógica em tempos de emancipação de sujeitos. In: D'ÁVILA, Cristina Maria; VEIGA, IIma Passos Alencastro (org). Didática e Docência na educação superior: implicações para a formação de professores. Campinas, SP: Papirus, 2012.

VANDERLEI, Marcia de Oliveira Torres. Discursos sobre a prática: o processo de formação do professor do ensino superior sem a formação pedagógica. 2012. 111 f. Dissertação (Mestrado em Educação) - Universidade Metodista de São Paulo, São Bernardo do Campo, São Paulo, 2012.

VEIGA, IIma Passos Alencastro. Por dentro da Didática: um retrato de três pesquisas. In: ENCONTRO NACIONAL DE DIDÁTICA E PRÁTICA DE ENSINO-ENDIPE, 5., 2010, Belo Horizonte. Anais do XV Encontro Nacional de Didática e Prática se Ensino-ENDIPE. Belo Horizonte: UFMG, 2010. 